\title{
UMA PAUTA PÚBLICA PARA UMA NOVA TELEVISÃO BRASILEIRA
}

\author{
Regina Mota
}

\section{RESUMO}

O objetivo do presente artigo é apresentar alguns elementos conceituais de uma "pauta pública" dos meios de comunicação no Brasil, em particular da televisão. Inicialmente se tecem algumas considerações sobre a importância da participação da sociedade para formular a programação televisiva, de uma forma que seja uma participação cidadã; em seguida, a partir de depoimentos de acadêmicos e profissionais liberais, apresenta-se alguns elementos dessas participação cidadã e pauta pública na televisão. O texto encerra-se considerando que, diferentemente do que os profissionais da comunicação consideram, há no Brasil uma demanda por uma televisão assertiva, que considere e apresente interesses sociais de longo prazo de maneira reflexiva e transformadora.

PALAVRAS-CHAVE: televisão; pauta política; políticas públicas; mídia eletrônica.

\section{INTRODUÇÃO}

O presente artigo coloca em debate algumas questões relativas ao desconhecido universo da televisão pública no Brasil. Há 12 anos defendi dissertação de mestrado (MOTA, 1992) sobre o tema, praticamente virgem no cenário nacional. A pesquisa refez toda a trajetória da constituição e organização do Sistema Brasileiro de Telerradiodifusão, divido até então entre a exploração privada ou comercial e estatal. O trabalho registrou a emergência do conceito de "público" no processo constituinte como uma via alternativa para estabelecer critérios às novas concessões de rádio e televisão. Foram pesquisados os anais da Constituinte, as audiências públicas e documentos propostos pelos partidos políticos. Até o início da década de 1990, portanto, nem sequer havia qualquer literatura específica sobre o tema, já que o objeto tampouco existia definido. A regulamentação dos artigos da Constituição brasileira de $1988^{1}$ praticamente não ocorreu, da mesma forma que a elaboração de

1 Sobretudo o contido no Título VIII, "Da ordem social", Capítulo V, "Da comunicação social", artigos 220 a 224. O artigo 223, especificamente, institui o sistema público de rádio e televisão nos seguintes termos: "Compete ao Poder Executivo outorgar e renovar concessão, permissão e autorização para o serviço de radiodifusão sonora e imagens, observado o princípio da complementaridade dos sistemas privado, público e estatal" (BRASIL, 1988, p. 95; sem grifo no original). uma nova lei que viesse a substituir o Código Nacional das Telecomunicações, lei de 1962 e que continua vigente. Minha pesquisa atual, “TV pública no Brasil: a construção de um projeto ético e estético" ${ }^{2}$, retoma e amplia a reflexão do tema em novas bases, já que a idéia da criação de um sistema público de televisão no Brasil vem aos poucos ganhando espaço na mudança em curso nas televisões estatais, culturais e educativas organizadas em torno da Associação Brasileira de Emissoras Públicas, Educativas e Culturais (ABEPEC). Infelizmente, o termo "público" associado à televisão nesse contexto é mais uma

2 Este artigo diz respeito a apenas uma parte da pesquisa em curso, que tem como objetivo ampliar a discussão conceitual do termo "público" associado à televisão. A escolha da expressão "pauta pública" deve-se ao fato de reconhecer na pauta um dispositivo do modo de realização da televisão em geral, privada ou estatal. Na investigação, essa discussão vincula-se menos aos conteúdos jornalísticos e mais à sua linguagem construída em imagens e sons. A pesquisa desdobra-se também em uma reflexão sobre os retratos veiculados no audiovisual (cinema, televisão e documentários em vídeo ou película), que contém uma potência identitária e singular daquilo que qualificamos de uma televisão brasileira. Para isso, foram estudados mais de 30 filmes e programas de televisão, bem como textos, manifestos e críticas que tratam da questão. Ainda a necessidade de pensarmos as representações do país e de seu povo nesses meios levou-nos a rever também alguns textos clássicos sobre sua formação, exemplares dos limites e possibilidades de retratar e explicar, pelas causas e efeitos, a afirmação de nossa identidade racial, cultural e política.

Rev. Sociol. Polít., Curitiba, 22, p. 77-86, jun. 2004 
griffe do que propriamente um projeto político. Tanto do ponto de vista jurídico ou legislativo como do ponto de vista da autonomia administrativa, política e financeira, a maioria dessas emissoras continua submetida aos interesses e limitações dos governos estaduais, a que quase todas estão vinculadas.

Nos últimos cinco anos, por outro lado, vem ocorrendo um movimento contínuo e crescente de mudanças conceituais nas televisões estatais e concessões de canais educativos no Brasil. O fenômeno é uma reação dessas emissoras ao atraso na legislação, à constante ingerência administrativa dos governos estaduais e ao eterno problema do financiamento dessas instituições. Obrigatoriamente, essas mudanças requerem um novo pensamento, cuja bandeira assumida foi a construção de um projeto de televisão pública para o país, a exemplo daquilo que já existe no resto do mundo desenvolvido, tendo como referência principal o modelo europeu, encarnado na BBC inglesa. Tive a oportunidade de participar de e colaborar em vários encontros nacionais e acompanhar ativamente o processo que instigou essa reflexão conceitual. Um primeiro problema que se delineia no processo é como envolver o interessado no debate, razão de ser de todo e qualquer serviço de utilidade pública, que é o cidadão, cujo interesse difuso deve ser atendido.

\section{O DEBATE MIDIÁTICO}

Um dos mais importantes temas de nossa sociedade é o debate midiático, ou a necessidade de refletir-se sobre a importância dos meios de comunicação na vida do cidadão. Há um pressuposto generalizado segundo o qual quem produz informação na imprensa escrita, no rádio ou na tevê sabe o que interessa aos leitores, ouvintes e telespectadores. Isso porque quem produz essas informações são profissionais treinados para pautar, apurar, redigir ou produzir informações, dentro de regras definidas pela técnica jornalística. As medidas de audiência e o consumo de jornais e revistas seriam evidências de que o mundo da informação produzida funciona. No mais, restam aos leitores ativos as mensagens eletrônicas e as seções de cartas, espaço em que podem manifestar satisfação ou não com aquilo que lhes chega às mãos, olhos e ouvidos.

A questão é ainda mais grave no caso da televisão, que se mostra totalmente surda a qualquer tipo de interação que não seja a pesquisa de audiência e a busca pela satisfação do gosto médio. Não há qualquer tipo de interesse pela demanda, qualificada ou não, que possa vir de indivíduos ou de grupos mais ou menos organizados.

Quando há debate midiático, ele põe-se na perspectiva de especialistas, profissionais da área ou proprietários dos meios eletrônicos. A meu ver, para que o telespectador/leitor compreenda a importância da mídia em seu cotidiano, o debate deve ser pautado pela perspectiva de seus interesses, assim como são pautados os temas da saúde, da educação, do transporte ou dos benefícios sociais. Se a comunicação é um direito do cidadão, isso apresenta para a sociedade e para o poder público a necessidade de criar políticas públicas direcionadas ao setor. Mas isso apenas ocorrerá quando o cidadão dominar a matéria e puder opinar e deliberar a seu respeito.

No momento, o Brasil inicia timidamente a discussão de um modelo de televisão digital para o país, privilegiando a tecnologia, para fazer face à disputa de mercado travada entre os que detêm os atuais padrões de digitalização. Essa seria uma oportunidade para rever-se a legislação do setor de telecomunicações, já que a mudança remodelará todos os serviços oferecidos pelos meios eletrônicos, bem como as formas de acesso a ele. O debate deve ser ampliado para a sociedade e, portanto, são necessárias a produção e a divulgação de informação sobre os possíveis impactos da digitalização da televisão na vida social, assim como o estabelecimento de meios efetivos de escuta de todos os setores, como forma de contemplar a inclusão de interesses no desenho de uma política pública de mídia eletrônica e digital. Só uma mobilização em grande escala poderia subsidiar uma política capaz de alterar em definitivo a comunicação brasileira, permitindo o seu desenvolvimento rumo ao acesso coletivo à nova tecnologia, considerando sua característica reversível e interativa.

\section{QUAL TEVÊ?}

Uma das primeiras questões que podem orientar o debate é saber de qual televisão falamos. Há um outro pressuposto generalizado sobre o caráter genuíno da televisão no Brasil: temos uma tradição de mais de 50 anos de formação técnica e de criação de formatos reconhecidos e premiados em todo mundo, além de uma razoável indústria de produtos de exportação. Isso coloca 
o Brasil em lugar de destaque na produção voltada para a mídia eletrônica.

Isso não quer dizer que esse modelo de televisão, que gerou os sistemas de exploração e sua legislação, seja minimamente avançado. Ao contrário, ele favorece o oligopólio e a concentração das audiências nas redes privadas, alimentadas pelas receitas advindas da veiculação de publicidade. Não se pode tratar dessa questão sem levar em conta o próprio serviço de utilidade pública da televisão, hoje majoritariamente explorado pela iniciativa privada. Por isso, é preciso pensar a dimensão pública da televisão, tanto do ponto de vista conceitual como das regras capazes de viabilizar sua efetividade.

Além disso, é desnecessário importar qualquer tipo de modelo exógeno europeu ou americano, cujo sistema público de radiodifusão está em crise e decadência; o que é relevante, na verdade, é considerar problemas que são comuns aos países latino-americanos, que fornecem dados interessantes, considerando os aspectos políticos de soberania, em particular no Cone Sul. O Chile, por exemplo, tem duas redes nacionais públicas de maior audiência, em contraposição às emissoras privadas, que sofrem com problemas financeiros crônicos. O caso chileno deve-se ao modelo implantado durante o regime militar, que permitiu ao Estado, juntamente com as universidades, o monopólio da exploração até 1989, quando se privatizou pela primeira vez uma emissora naquele país (FUENZALIDA, 2000, p. 26).

No Brasil, os militares favoreceram a exploração privada ao construir a infra-estrutura de telerradiodifusão (estações repetidoras, satélites etc.) para implantar as redes nacionais (MOTA, 1992, p. 43). Já a Colômbia operava em um sistema estatal único até 1996, veiculando programas de produtoras privadas. A partir de então foram criados canais comerciais, além de canais locais e comunitários. Germán Rey (2002, p. 113) avalia que as televisões regionais da Colômbia são uma boa expressão de como o caráter público deixou de associar-se apenas ao aspecto nacional: "A região transcendeu a definição geográfica, passando a ser um espaço histórico, uma esfera de desenvolvimento e uma experiência comum [...]. É como se esse colapso do predomínio nacional tivesse alterado a ótica e as proporções da sociedade, fazendo entrar na paisa-gem televisiva as televisões locais e comunitárias”.
As recentes coletâneas de textos sobre a televisão pública na América Latina ${ }^{3}$ são testemunhos de idéias que vinculam o exercício da política e a comunicação eletrônica ao desenvolvimento de processos sociais. A importância dessa reflexão surge devido à origem das televisões estatais, criadas como projetos nacionais para cumprir a missão de integrar simbolicamente esses países. Segundo Rey, "a televisão irradiou essa idéia de caráter nacional, do mesmo modo que transmitira suas mensagens pelas ondas hertzianas; inclusive nessa capacidade os governos viram um aliado. Eram transmissões sem retorno, ou seja, de uma só mão: dos centros para as periferias" (idem, p. 112).

No Brasil, o movimento de integração nacional via televisão proporcionou um modelo de mídia eletrônica concentrado de audiência e de controle da comunicação no período da ditadura. Apesar de relativizado nos último vinte anos, não foi possível reverter o seu caráter privado e comercial, cuja marca é a ausência de uma legislação que possa reorientá-lo para a vocação pública.

\section{A DIMENSÃO PÚBLICA}

O que caracteriza o caráter público da televisão são, resumidamente, três aspectos fundamentais: a natureza jurídica das emissoras educativas e culturais, as formas de financiamento do sistema e o controle público sobre o serviço. Uma dificuldade ao pensar-se a televisão pública no Brasil é a falta de clareza do significado do termo que a

3 Essas coletâneas de textos organizados a partir de seminários sobre o tema "televisão pública" são registros do pensamento latino-americano sobre a amplitude política da dimensão pública da televisão para a América Latina. Esse movimento é contrário ao que vem ocorrendo nos países em que as legislações previram uma exploração pública desde a sua origem, como é o caso exemplar da $\mathrm{BBC}$, na Inglaterra. É importante perceber que, nesse debate, não está mais em causa tanto o papel do Estado, como nos países europeus, mas a instância da sociedade como definidora de parâmetros para uma comunicação eletrônica que possa incluir o que está ausente dos interesses comerciais atendidos pelas televisões privadas. Portanto, não cabe aqui repetir o grande debate da moderna esfera pública como instância de controle do poder público, mas a necessidade de ampliar-se a circulação de idéias e de novas identidades que surgem da periferia, das margens das estruturas centralizadas e oligopolizadas dos sistemas de mídia nesses países, que lutam para estabilizar seus ainda frágeis processos de democratização (FUENZALIDA, 2000; RINCÓN, 2002). 
qualifica, já que, não apenas no âmbito da televisão mas em qualquer outro setor da socie-dade, o termo "público" remete-nos ao da ação do Estado 4 .

Essa é uma dificuldade real para pensar a dimensão pública como aquela que trata do que é comum a todos e, portanto, aquilo que tem interesse para a sociedade, que é sua destinatária e seu fundamento. No Direito Administrativo brasileiro, isso está declarado como um princípio geral, teórico e que, na prática, não conseguiu constituir-se como ação efetiva, garantida pelo poder público.

A idéia de uma pauta pública para estabelecer alguns critérios que poderiam orientar o debate dessa televisão nasce de uma abordagem enraizada, tanto do ponto de vista do conceito como das propostas, em questões que dizem respeito ao país. Se público é aquilo que é comum a todos, é possível depreender que o que é comum a todos é algo que nos é próprio. Nesse sentido, "próprio" é adequado, apropriado à realidade, o que na televisão concretiza-se pela presença dos problemas locais e regionais; nas marcas da diferença materializada na diversidade de pessoas, de visões e de idéias nascidas da experiência da lida cotidiana nas cidades e no campo; na pluralidade de expressões culturais e artísticas, que não podem ser limitadas ao que a mídia reconhece e legitima.

"Próprio" é também tudo aquilo de que eu posso apropriar-me e co-produzir, sugerindo pautas e programas, criticando e atuando ao participar de instrumentos de acesso à televisão, como conselhos, comitês de telespectadores, ouvidorias etc. Não há justificativa plausível para a inexistência desses instrumentos nas televisões,

\footnotetext{
4 No Brasil, o senso comum atribui o caráter público às instituições e ações do Estado, acrescido de um significado pejorativo, já que tudo que se associa ao termo, como a saúde pública, a educação pública ou o transporte público, destina-se àqueles cidadãos que não têm meios para aceder tais serviços no âmbito privado. Genericamente, poderíamos afirmar que público é aquilo que sobra para os pobres, excluídos e para a massa de sub-assalariados do país. Só muito recentemente um conceito afirmativo de público associado à dimensão daquilo que é comum a todos e que, portanto, requer participação e contrapartida da sociedade, vem ganhando espaço e disseminando-se como discurso. Para que ele tome forma no imaginário do brasileiro, é necessário que seja posto em ato.
}

incluindo as estatais, educativas e públicas. A grande maioria das emissoras que se dizem públicas não opera os seus dispositivos descentralizadores, que acabam existindo para inglês ver, apenas na legislação, já que boa parte nem sequer instala os seus impotentes conselhos. Nos dados fornecidos pela ABEPEC em 2004, apenas a Fundação Padre Anchieta, mantenedora da TV Cultura de São Paulo, a TV Educativa do Rio de Janeiro e a Fundação Cultural Piratini, mantenedora da TV Educativa de Porto Alegre, contam com conselhos efetivos e atuantes como parte da sua administração (cf. ABEPEC, 2004). Mesmo que o significado dessa atuação seja restrito, a atividade desses conselhos traduz um desejo de imprimir-se uma dimensão pública por meio da representação, ainda que clássica, da sociedade, que ali pode zelar pelos seus interesses.

Mas o que realmente se materializa na televisão para o telespectador é a percepção de "próprio" no sentido daquilo que é nosso, genético, genuíno, inventivo, criativo e inovador. Não é preciso reconhecer uma ruptura na linguagem da televisão, mas o que na programação contém um germe do novo, que aponta para novas possibilidades de tratamento da realidade e da consideração do telespectador enquanto cidadão, em que o último pode-se ver na programação e não apenas uma sua representação caricata, seja como genérico habitante do Sudeste do país ou folclorizado na tipificação regional. Todas essas noções de "próprio" colaboram para produzir uma identidade e a relação de patrimônio que realiza a dimensão pública.

\section{DESAFIOS DE UMA PAUTA PÚBLICA}

Mais do que qualquer outro gênero da televisão, o jornalismo volta-se inteiramente para o presente, reforçando a característica mais evidente do meio eletrônico que é o seu "processo aberto em andamento", como afirma Arlindo Machado (1986, p. 89). A possibilidade de enunciar algo simultaneamente à sua decodificação faz que o jornalismo seja atraído para o acontecimento, para o testemunho do fato, mais do que por seu significado ou sua importância e, sobretudo, por sua relevância para a sociedade.

Observando o telejornalismo das emissoras privadas e mesmo o das públicas, podemos constatar a quase ausência de passado e futuro nas pautas. Temas que poderiam ser de extremo interesse público, não meramente factuais, são 
classificados como "matéria fria". Nesse sentido, o jornalismo não é previdente, não se volta para a pesquisa sistemática, que pode evidenciar questões que deveriam ser pautadas cotidianamente, mesmo que não haja morte, atropelamento, sangue, violência ou corrupção em seu entorno. $\mathrm{O}$ desafio do jornalismo público é ser capaz de pautar o que é essencial à sociedade, contando com a sua preciosa colaboração.

As redações recebem diariamente inúmeras mensagens eletrônicas, cartas, telefonemas, em que se expressa o desejo dos telespectadores de influenciar de alguma forma nos conteúdos dos telejornais. Essas informações, muitas vezes preciosas, quase nunca são ouvidas e muito menos refletidas como matéria-prima para a pauta, mas tratadas burocraticamente. Ao telejornalismo só interessa o press-release. É sobre ele que vão se digladiar jornalistas e câmeras das diversas emissoras. Nas tevês públicas e educativas, diferentemente, dedica-se maior espaço a fatos gerados fora do centro da política e da economia, como as questões de meio ambiente ou de movimentos sociais, deixando entrever um conceito de jornalismo público que inclui uma dose de conteúdo social na pauta.

Uma pauta pública poderia promover a alteridade, a consciência da existência do outro. É o que faz a boa tradição do documentário cinematográfico e televisual, ao aproximar e revelar universos distantes, seja pela geografia, seja pela existência à margem dos acontecimentos "centrais". A renovação desse gênero deu-se a partir das atualidades da televisão, no final dos anos 1950, quando a cinematografia mundial foi renovada pelos sons e imagens dos cinemas novos, do Cinema Verdade e do Cinema Direto. A televisão, ao contrário, ao domesticar a sua "câmera viva", promove um fenômeno de equalização, em que tudo e todos tornam-se iguais. Rigorosamente, pode-se mudar de um telejornal para o outro sem que se perceba qualquer tipo de mudança, a não ser a do cenário.

O tratamento das pessoas nos telejornais é quase sempre categórico: o político, o governante, o menino da creche, a vítima, o criminoso, o flagelado, o empresário, o artista. Poderia ser emblemático, caso fosse possível dar a cada personagem a dimensão de sua singularidade esta sim generalizável. Para que as pessoas possam identificar-se, é preciso que se reconheçam nos retratos humanos e nas histórias que o jornalismo torna público todos os dias.

Nesse reconhecimento reside a idéia da própria existência pública de todos os setores da sociedade e não apenas a dos "poderosos" ou a dos "criminosos", que perfazem até $90 \%$ de tudo o que é noticiado na mídia do país (cf. Seminário Jornalismo Público, 2001). Portanto, o que uma pauta pública pode promover junto ao telespectador é a consciência de sua própria existência, permitindo que se conceba a televisão como algo apropriável, útil, benéfico e sobre o que ele pode e deve deliberar.

\section{O INTERESSE PÚBLICO NA PERSPECTIVA DO CIDADÃO}

Na última década, vários jornais e televisões norte-americanos saíram em busca de um novo conceito de jornalismo que estivesse em sintonia maior com os interesses das populações a que se endereçavam. Uma pesquisa feita em 1994 indicou que apenas $25 \%$ das pessoas concordavam com a afirmação de que a mídia ajuda a resolver os problemas da sociedade. Alguns jornalistas, como Davis Merrit, assumiram a tarefa de refazer a credibilidade de sua profissão, fundando um movimento que ligava o jornalismo à cidadania. Jay Rosen, outro militante desse movimento, afirmou que "o jornalismo pode e deve ter um papel no reforço da cidadania [citizenship], melhorando o debate público e revendo a vida pública” (Rosen apud TRAQUINA, 2001, p. 172).

O "Jornalismo Cívico", nome dado ao movimento, passou então a buscar novas práticas, o que evidentemente incluía a participação efetiva dos interessados, ou seja, dos cidadãos. A partir de entrevistas em profundidade feitas com os habitantes e de intercâmbios de idéias, muitos tiveram a oportunidade de estabelecer contatos e conhecer representantes de diversos grupos, fazer reportagens em que se evidenciavam questões de conflito, tendo sido publicados artigos sobre histórias de pessoas que tinham conseguido contribuir positivamente para a coletividade.

Nas eleições de 1992, o jornal Charlotte Observer, da Carolina do Norte, promoveu uma sondagem com mil pessoas para estabelecer uma agenda dos cidadãos, em que foram reconhecidos seis problemas que orientariam a cobertura jornalística dos candidatos. Basicamente, o movimento e seus resultados mostraram a 
necessidade de escuta e de criação de instrumentos capazes de dinamizar a participação dos cidadãos na vida pública. Isso se deu em empresas privadas e hoje o movimento do Jornalismo Cívico congrega mais de 200 projetos nos Estados Unidos.

No Brasil, há uma tradição de jornalismo em que os profissionais figuram como representantes dos interesses da sociedade. Não é incomum que uma opinião pessoal transforme-se em editorial, como atesta o comportamento de alguns "âncoras" da tevê brasileira. Assim, não há razão para perguntar-se o que os leitores e telespectadores esperam da mídia, já que os jornalistas e editores, ao que tudo indica, sabem o que deve ser noticiado. Qualquer tentativa de discutir-se a possibilidade de participação da sociedade civil no controle da programação da tevê é vista como uma ação repressora, de censura, constituindo uma ameaça à liberdade de expressão.

Washington Novaes relata uma experiência no Diário da Manhã, vivida por ele em Goiânia, na década de 1980, em que o dono do jornal permitiu a criação de um conselho de leitores integrado por 50 pessoas, todas convidadas e escolhidas pelo Conselho Editorial. Eram representantes de partidos políticos, entidades da sociedade civil, sindicatos patronais e de trabalhadores. Novaes classificou a experiência como extraordinária, "[...] porque mostrou, principalmente, que a sociedade pensa que um jornal deve ser bastante diferente daquilo que nós, jornalistas, pensamos" (NOVAES, 1988, p. 98). A circulação do jornal quintuplicou e a experiência durou um ano e meio, apesar de bemsucedida. Esse parece ser um caso isolado no cenário da imprensa brasileira, pouco preocupada com uma possível parceria com o público de cidadãos.

Todos os caminhos do jornalismo público apontam, a meu ver, para os seus interessados: os leitores, os telespectadores, ou seja, o cidadão. Por isso, a pesquisa que atualmente desenvolvo entrevistou em profundidade 17 pessoas ${ }^{5}$, perguntando o que seria "interesse público" hoje na televisão brasileira, do ponto de vista da inserção do entrevistado na sociedade.

5 A pesquisa conta com a colaboração da bolsista de iniciação científica Renata Antunes, responsável pelo recolhimento dos depoimentos aqui utilizados. No período de setembro a novembro de 2002, foram feitas 15 entrevistas individuais com os seguintes profissionais: Carlos Ranulfo Melo e Vera Alice Cardoso, cientistas políticos e professores
Algumas respostas foram unânimes: a pauta pública, além de informar, deve levar à reflexão, a uma mudança de comportamento e de mentalidade.

Apesar das dimensões da empreitada, esse é o ponto para que convergem o tema e seu tratamento, já que não se quer mais a imediata satisfação do telespectador, mas o seu envolvimento com o problema. Como defendeu o professor e jornalista Elton Antunes, "assuntos de interesse público são assuntos que fogem da lógica do mercado. É necessário abordar temas que não são de interesse inicial do público, mas é papel do jornalismo contrariar o público com assuntos que lhe são de extremo interesse. Mesmo que esses interesses não sejam imediatos, deveriam ser tratados assim mesmo. O jornalista cumpre o seu papel se prestar atenção aos movimentos, às mudanças e ficar mais atento para estranhar o que está debaixo do seu nariz. Se o jornalista não se espanta, o telespectador também não se espanta" (ANTUNES, 2002).

As entrevistas forneceram dois tipos de dados para a análise: de um lado, sugeriram alguns conceitos gerais que deveriam orientar a pauta de interesses públicos na televisão; de outro, mostraram temas específicos que devem ser sempre privilegiados. $O$ surpreendente nesse levantamento é a disposição dos entrevistados em pensar e

do Departamento de Ciência Política da Universidade Federal de Minas Gerais (UFMG); Elton Antunes, Professor do Dept. de Comunicação Social da UFMG; Joaquim Antônio César Mota, Coordenador e ProfessorAdjunto de Pediatria Clínica no Hospital de Clínicas da UFMG; João Gabriel Marques, músico, Professor de Clínica Médica da UFMG; Antônio Emílio de Araújo, Professor do Dept. de Engenharia da UFMG e membro da Comissão Permanente de Vestibular; Geraldo Caldeira, psicanalista especializado em Psicologia Médica; Maria de Lourdes Gouveia, Professora de Filosofia da Pontifícia Universidade Católica de Minas Gerais (PUC-MG); Alfredo Gontijo, Professor do Depto. de Física da UFMG; José Ricardo de Oliveira, especialista em Clínica Médica e Bioética da PUC-MG e Coordenador de Residência Médica do Hospital SEMPER; Ricardo Fenatti, Professor do Dept. de Filosofia da UFMG; Paulo Marguti, Professor do Dept de Filosofia da UFMG e Coordenador do Grupo de Pesquisas sobre o Pensamento Filosófico no Brasil; Regina Helena Alves, Professora de História da UFMG; Menelick de Carvalho, Professor de Direito Constitucional da UFMG; Carlos Roberto Jamil Cury, filósofo; Nelson Vaz, professor do Dept. de Imunologia da UFMG e Cremilda Medina, jornalista e professora do curso de Comunicação Social da Universidade de São Paulo. 
fornecer sugestões sobre um tema que não tem sido pautado para o público de não-especialistas. A primeira descoberta da pesquisa é que há muito mais interesse e expectativa com relação à televisão do que imaginam os seus profissionais, especialistas, teóricos e críticos.

Não há dúvida de que um conceito de interesse público em uma sociedade complexa como a brasileira é algo de difícil tradução quando se trata do bem comum. Uma primeira diferenciação é que interesse público e o interesse do público podem não coincidir ou se chocar, como sugere Antunes. Por isso, no lugar de prevalecer uma visão normativa e delimitadora do que são esses interesses, vale mais investir nas inúmeras questões e em idéias que podem ser concretizadas na linguagem, nos conceitos e na ampliação das formas de acesso à mídia eletrônica.

\section{LUGAR DE ENCONTRO}

A partir dos depoimentos recolhidos, selecionamos algumas das principais noções, conceitos e sugestões dos entrevistados, que apontam para um reconhecimento da potência latente da televisão, em um país como o Brasil, contemplada nos mais diversos aspectos da existência humana, do enriquecimento do imaginário e da qualidade de vida.

Por exemplo, para o filósofo Ricardo Fenatti, as preferências coletivas só se tornarão visíveis se se puder viver a experiência do público compreendido como lugar de encontro. As pessoas estão sequiosas por essa experiência, porque há uma perda da dimensão pública da existência, impossibilitando-as de conviver na cidade. O ser humano precisaria criar novas formas para interpretar a sua existência, pois existe um enorme abismo entre as necessidades simbólicas e os recursos simbólicos disponíveis para expressá-las (FENATTI, 2002).

Fenatti exemplifica essa necessidade relembrando que, há quarenta anos, havia nos jornais colunas de crítica literária escritas por especialistas, que analisavam os lançamentos, exercendo o papel de tradutores culturais ou mediadores entre o autor e o público-leitor. Essa idéia mais totalizada de cultura, segundo ele, perdeu espaço, e os suplementos literários tornaram-se quase técnicos, praticamente voltados para pessoas já iniciadas. Essa forma superficial de produzir cultura, a seu ver, contribui para a formação de guetos culturais que não se comunicam. "A tevê pública tem potencial para funcionar como uma tradutora cultural, um instrumento que seria capaz de beber nos mananciais mais ricos da cultura e distribuir esses bens culturais. Podemos discutir na televisão assuntos que sirvam de estímulo para que as pessoas conversem consigo mesmas" (idem).

Essa idéia é corroborada pelo músico e médico João Gabriel Marques, para quem a televisão pública pode oferecer meios para que os telespectadores pensem, reflitam e desenvolvam sua sensibilidade. Para ele, a qualidade de vida está intimamente relacionada ao desenvolvimento da sensibilidade artística, porque a arte permite ampliar o repertório de experiências e conhecimentos humanos. Em suas pesquisas e atividade clínica, Marques observa que mais de $50 \%$ dos problemas de saúde estão relacionados ao modo de vida das pessoas. Por isso, ele acredita que tudo o que for feito para melhorar a qualidade de vida terá impacto direto na saúde das pessoas (MARQUES, 2002).

Segundo Marques, "nós vivemos uma realidade televisiva que é o avesso radical de tudo isso. As imagens grotescas produzidas pela tevê são excrementos da consciência, o que só pode contribuir para a sua degeneração". A arte, na opinião do também professor, é uma provocação, porque faz pensar, "mas é preciso liberar e não dominar a sensibilidade do telespectador, sujeitando-o às banalidades dos melodramas, programas de auditório e exploração da vida privada" (idem).

$\mathrm{O}$ instrumento para ampliar essa sensibilidade seria a produção de memória, na visão da filósofa Maria de Lourdes Gouveia. A cidade deveria ser privilegiada no sentido de preservar suas memórias no espaço público. Gouveia defende a necessidade de construir-se um olhar penetrante, que procure o invisível do visível para produzir um diálogo reflexivo: "O que vejo como possível é fundamentar o arbítrio no diálogo reflexivo e significativo, articulado às demandas públicas. Isso me lembra uma querela entre Lênin e Rosa de Luxemburgo. Lênin propunha ações em nome dos operários e Rosa perguntava: 'o que você sabe deles?'. Todo serviço público é transversalmente situado nesta questão: você nunca pode ter certeza de que uma demanda é real ou de qual é o público de que estamos tratando" (GOUVEIA, 2002).

Assumir esse limite é também tarefa de uma pauta pública em que fique explícito não apenas o 
que se sabe como também aquilo que não se sabe. É por isso que o cientista Carlos Ranulfo de Melo acredita que essa pauta deve estar a serviço do aprimoramento da democracia. Para ele, a televisão poderia desenvolver abordagens e estratégias que permitissem ao telespectador colocar-se no lugar do cidadão. "Se você pensa em democracia, em ter uma vida democrática, alguns valores são importantes: prezar a igualdade e a liberdade e, principalmente, prezar o outro, a afirmação do outro. E o ‘outro' não é o meu parente ou vizinho; o outro é aquele que eu não conheço e que, do ponto de vista do Direito, é igual a mim. Isso é crucial para o desenvolvimento da democracia" (MELO, 2002).

Como espaço privilegiado de formação de opinião, a tevê poderia ter a missão de promover uma cultura cívica, hoje inexistente no país. Segundo o cientista, não há um fundamento empírico que justifique o grau de desconfiança generalizada do brasileiro em relação a tudo e a todos, a não ser em razão dos constantes escândalos veiculados e promovidos pela mídia. Diante de tão freqüentes denúncias, torna-se difícil reconhecer qualquer esforço construtivo dessa cultura, que deveria gradualmente ocupar o lugar da corrupção, do abuso de poder ou das constantes evidências de apropriação privada do Estado.

Para o filósofo Carlos Roberto Jamil Cury, a tevê pública envolve a dialética entre Estado e sociedade, sendo esta última reconhecida como sujeito e não como mero recipiente. $\mathrm{O}$ mesmo considera Menelick de Carvalho, especialista em Direito Constitucional, acrescentando que a televisão pública pode ser um canal para que as pessoas sintam-se co-autoras das normas que regem a própria vida e possam formar uma opinião pública sobre seus direitos. "Em nosso processo histórico, continuamos com práticas autoritárias. O Congresso não legisla porque as pessoas não votam pensando nisso; elas querem o asfalto da rua onde moram e uma botina nova. A tevê é um espaço da democracia, um espaço em que se faz a discussão sobre as diferenças. A agenda dessa tevê deve ser formada com a participação da sociedade e da cidadania, com uma pauta que mobilize efetivamente as pessoas".

\section{O PENSAMENTO BRASILEIRO}

O filósofo Paulo Marguti propõe para a pauta pública um desafio que possa trazer à tona as potencialidades do pensamento filosófico no Brasil, hoje pouco estudado e valorizado. Coordenador de um grupo de estudos sobre o tema, Margutti vem estudando como o brasileiro vê-se. Essa autoimagem liga-se muito à obra Raízes do Brasil, do historiador Sérgio Buarque de Hollanda, e às obras do antropólogo Roberto da Matta e do sociólogo Gilberto Freire. "Existe um preconceito no país de que o brasileiro não tem cabeça filosófica, portanto não merece ser estudado. A história intelectual do Brasil é desinteressante por esse motivo. Para reverter essa tendência, as pessoas devem ser estimuladas a estudar os acontecimentos, as manifestações intelectuais e os diversos pensamentos desenvolvidos no país. Isso pode promover uma transformação nas pessoas, pois permite que elas descubram algo de interessante ao olhar para dentro de si mesmas, ao olhar para a cultura brasileira" (MARGUTI, 2002).

$\mathrm{Na}$ visão de Margutti, o brasileiro tem uma atitude perante a vida que o leva a acreditar mais na ação que no sistema. Isso se daria em três domínios completamente originais, que estão à margem da filosofia tradicional e que nós ignoramos: ao invés de construir sistemas, o brasileiro busca a solução no místico ou na transcendência ou na emoção estética. Quando ele é ateu, a estética resolve. "O brasileiro é cético porque vive numa sociedade na qual não acredita. Ele não faz filosofia porque pensa não ser capaz, quando na verdade ele não faz porque é cético. A nossa situação cultural faz aceitemos fazer as coisas de um jeito, embora tenhamos complexo por fazê-las assim. Não gostamos do nosso jeito de fazer e por isso não observamos. Mas, se começarmos a olhar, descobriremos que há coisas interessantes no nosso jeito brasileiro. E a tevê pública é um espaço para essas descobertas" (idem).

Cremilda Medina, jornalista e professora do curso de Comunicação Social da Universidade de São Paulo (USP), indica um caminho para a realização dessas propostas: o jornalista tem que resistir para desenvolver um jornalismo ético, para criar uma nova imagem e um novo olhar sobre a realidade. Para isso, precisa envolver-se intimamente com as histórias, sem ser sensacionalista ou voyeur. Medina aponta ainda para a necessidade de abandonar-se a pauta inercial, subproduto do press-release, e descobrir, a partir das demandas 
sociais, o desejo coletivo, que não estaria nos grupos organizados e sim nos indivíduos desorganizados (MEDINA, 2002).

Fenatti sugere ainda que se dê um novo tratamento aos temas, para buscar uma proximidade: segundo ele, entre a tevê e o público deve ser evitado o distanciamento, pois ele é o contrário da razão pública. Esse ideal deve ser discutido com a sociedade e deve ter uma dimensão avaliativa, de construção e de utopia. "É um ideal que projetamos e a que temos que nos ajustar. Devemos perguntar-nos o que diz respeito ao público como um todo. Ao discutir Machado de Assis, por exemplo, é preciso dizer o que existe nele e que está presente em todos nós e como a compreensão de sua obra pode ajudar a compreender a nós mesmos" (FENATTI, 2002).

\section{POR UMA TELEVISÃO ÉPICA}

$\mathrm{Na}$ Odisséia, Homero relata como Ulisses precisou amarrar-se ao mastro de seu navio para não sucumbir ao canto das sereias e assim realizar o percurso civilizatório da natureza à cultura. Todos nós, como Ulisses, vamos à guerra, estamos em guerra, tentando garantir esse percurso, lutando contra a ameaça constante da barbárie.

O melhor registro dessa luta está na televisão, sobretudo no telejornalismo, que parece não se dar conta do tamanho e da grandeza de sua missão. As fórmulas repetidas pelos manuais copiados das emissoras norte-americanas reduzem a abordagem de milhares de temas, os inúmeros retratos humanos e a complexidade de conteúdo a uma técnica jornalística. Limites impostos à imagem, duração e articulação dos fragmentos da realidade impedem que as narrativas telejornalísticas possam singularizar os acontecimentos.

Ao buscar e revelar a significação histórica dos fatos, cada evento particular ganha sua dimensão universal. No lugar de categorizar o político corrupto, o jornalismo deveria ser capaz de captar o mito que o constrói e que nos oprime, já que boa parte da nossa realidade é constituída desses mitos, que, folclorizados e introjetados, orientam as escolhas coletivas e seus conseqüentes modelos, erigidos na cultura, na política e na vida social.

Essa dimensão épica é exemplar nas transmissões do futebol, seja nos telejornais ou nas partidas ao vivo, em que o que se vê é a verdadeira tragédia grega, com o embate entre bravos guerreiros. A emoção dessas partidas já era captada pela câmera das atualidades cinematográficas de Carlos Niemeyer, nos idos dos anos 1950 e 1960, projetadas antes dos filmes, nas sessões de cinema. Os closes na geral retratavam o sofrimento, a alegria e o desespero dos torcedores, participando de cada instante, vivendo a partida no limite da vida ou da morte.

O futebol no Brasil é épico porque reproduz, no embate e na festa, parte de nossas crenças, além de ser uma prova de nossa capacidade de superação de entraves. Marco Antônio Coelho, diretor de jornalismo da TV Cultura de São Paulo, sugeriu que "o futebol fosse estudado para que pudéssemos pensar a nossa relação com a imagem, com o movimento, com o cotidiano, com o que nos interessa. Em nosso caso, o futebol tem interesse público, porque faz parte da cultura brasileira. O jeito como se pratica esse esporte é o jeito como a gente canta e dança" (Seminário Jornalismo Público, 2001).

Para construir esse outro jornalismo, é preciso que ele assuma-se como aquilo que verdadeiramente é: a construção de uma narrativa, com momentos de passe de bola, de pênalti e gol. Os telejornais estruturam uma narrativa pretendendo que ela seja tão verossímil quanto a realidade que constroem. A análise da estrutura desses telejornais mostra que seus enredos são montados com momentos de extrema tensão, seguidos de distensão e um pouco de entretenimento, como sugere a boa regra do plot da dramaturgia.

No telejornal, a câmera só é utilizada para testemunhar o fato, quando ela poderia gerar o fato. A grande novidade dos cinemas novos, que surgiram nos anos 1960, era a possibilidade de criar um evento em torno da câmera, transformando-a em um personagem que aderia às pessoas e ao ambiente, criando novos planos na imagem e no som direto. Isso trouxe para as telas a vida singular das pessoas comuns, o som das línguas com seus sotaques e a nova geografia humana.

Portanto, quando falamos de uma programação que possa estabelecer uma nova relação com o público, isso pressupõe um deslocamento da sua consciência: de mero espectador, o público pode repensar a sua relação com o mundo e com a própria televisão. Essa complexidade só pode ser alcançada se houver opacidade na tela da televisão. 
Esta é a função da linguagem - a de fazer aparecer o dispositivo, ofuscando a sua transparência renitente (MACHADO, 1986, p. 58).

Somente assim será possível redescobrir as imagens do telejornalismo, para narrar, como afirmou Cremilda Medina, a morte, o genocídio, os povos desterrados pelas guerras, sem sensacionalismo ou voyeurismo e dar à vida a sua dimensão épica e sagrada.

Regina Mota (rmota@fafich.ufmg.br) é Doutora em Comunicação e Semiótica pela Pontifícia Universidade Católica de São Paulo (PUC-SP), Coordenadora da pesquisa "Televisão pública no Brasil, a construção de um projeto ético e estético" e Professora do Programa de Pós-graduação em Comunicação Social e do Departamento de Comunicação Social da Universidade Federal de Minas Gerais (UFMG).

\section{REFERÊNCIAS BIBLIOGRÁFICAS}

FUENZALIDA, V. 2000. La televisión pública en America Latina : reforma o privatización. Santiago de Chile : Fondo de Cultura Económica.

MACHADO, A. 1986. A arte do vídeo. São Paulo : Brasiliense.

MOTA, R. 1992. Televisão pública. A democracia no ar. Belo Horizonte. Dissertação (Mestrado em Educação). Universidade Federal de Minas Gerais.

1993. A televisão brasileira e a revisão da Constituição em 1993. Ciência Hoje, Rio de Janeiro, v. 16, n. 93, p. 18-20, ago.

2001. A épica eletrônica de Glauber. Um estudo sobre cinema e TV. Belo Horizonte : UFMG.

NOVAES, W. 1988. Ética e informação. In : ALMEIDA, C. (org.). TV ao vivo. São Paulo : Brasiliense.

REY, G. 2002. O cenário móvel da televisão pública. Alguns elementos do contexto. In : RINCÓN, O. (org.) Televisão pública : do consumidor ao cidadão. São Paulo : Friedrich Ebert Stiftung.

RINCÓN, O. (org.). 2002. Televisão pública : do consumidor ao cidadão. São Paulo : Friedrich Ebert Stiftung.

TRAQUINA, N. 2001. O estudo do jornalismo no século XX. Porto Alegre : UNISINOS.

\section{OUTRAS FONTES}

ABEPEC. 2004. Associação Brasileira das Emissoras Públicas, Educativas e Culturais. Disponível em: http://www.abepec.com.br/. Acesso em : 10.jun.2004.

ANTUNES, E. 2002. Entrevista concedida a Renata Antunes. Belo Horizonte, set.

BRASIL. 1988. Constituição da República Federativa do Brasil. Brasília : Câmara dos Deputados. Disponível em : http:// www.camara.gov.br/internet/legislacao/ constituicao/CFpdf/Constituicao.pdf. Acesso em : 10.jun.2004.

FENATTI, R. 2002. Entrevista concedida a Renata Antunes. Belo Horizonte, set.
GOUVEIA, M. L. 2002. Entrevista concedida a Renata Antunes. Belo Horizonte, set.

MARGUTI, P. 2002. Entrevista concedida a Renata Antunes. Belo Horizonte, set.

MARQUES, J. G. 2002. Entrevista concedida a Renata Antunes. Belo Horizonte, set.

MEDINA, C. 2002. Entrevista concedida a Renata Antunes. Belo Horizonte, set.

MELO, C. R. 2002. Entrevista concedida a Renata Antunes. Belo Horizonte, set.

Seminário Jornalismo Público na Rede Minas. 2001. Belo Horizonte, 22.jun. 